\title{
Selenium levels in cows fed pasture and concentrates or a total mixed ration and supplemented with selenized yeast to produce milk with supra-nutritional selenium concentrations
}

\author{
C. R. Stockdale, ${ }^{, 1,2}$ P. M. Shields, $†$ A. McKenna,‡ G. P. Walker, ${ }^{\star}$ F. R. Dunshea, $\S$ and P. T. Doyle* \\ *Department of Primary Industries, Future Farming Systems Research, Kyabram Centre, 120 Cooma Road, Kyabram, Victoria 3620, Australia \\ †Alltech Biotechnology Pty Ltd, 68-70 Nissan Drive, Dandenong South, Victoria 3175, Australia \\ ¥Tatura Milk Industries Ltd, PO Box 213, Tatura, Victoria 3616, Australia \\ SFaculty of Land and Food Resources, The University of Melbourne, Parkville, Victoria 3010, Australia
}

\begin{abstract}
Seventy multiparous Holstein-Friesian cows were fed different amounts of pasture and concentrates, or a total mixed ration (TMR), for $42 \mathrm{~d}$ in mid-lactation to test the hypothesis that the concentration of Se in milk would depend on the amount of Se consumed, when the Se is primarily organic in nature, regardless of the diet of the cows. Of the 70 cows, 60 grazed irrigated perennial pasture at daily allowances of either 20 or 40 $\mathrm{kg}$ of dry matter $(\mathrm{DM}) / \mathrm{cow}$. These cows received 1 of 3 amounts of concentrates, either 1,3 , or $6 \mathrm{~kg}$ of DM/ cow per day of pellets, and at each level of concentrate feeding, the pellets were formulated to provide 1 of 2 quantities of Se from Se yeast, either about 16 or $32 \mathrm{mg}$ of $\mathrm{Se} / \mathrm{d}$. The other 10 cows were included in 2 additional treatments where a TMR diet was supplemented with $1 \mathrm{~kg}$ of $\mathrm{DM} / \mathrm{d}$ of pellets formulated to include 1 of the 2 quantities of supplemental Se. Total Se intakes ranged from 14.5 to $35.9 \mathrm{mg} / \mathrm{d}$, and of this, the Se-enriched pellets provided 93,91 , and $72 \%$ of the Se for cows allocated 20 and $40 \mathrm{~kg}$ of pasture DM/d or the TMR, respectively. No effects of the amount of Se consumed on any milk production variable, or on somatic cell count, body weight, and body condition score, for either the pasture-fed or TMR-fed cows were found. Milk Se concentrations responded quickly to the commencement of Se supplementation, reaching $89 \%$ of steady state levels at $\mathrm{d} 5$. When milk Se concentrations were at steady state (d 12 to 40), each $1 \mathrm{mg}$ of Se eaten increased the Se concentration of milk by $5.0 \mu \mathrm{g} / \mathrm{kg}\left(\mathrm{R}^{2}\right.$ $=0.97$ ), and this response did not seem to be affected by the diet of the cows or their milk production. The concentration of Se in whole blood was more variable
\end{abstract}

Received July 4, 2010.

Accepted October 3, 2010.

${ }^{1}$ Current address: Department of Primary Industries, Future Farming Systems Research, Tatura Centre, 255 Ferguson Road, Kyabram, Victoria 3616, Australia.

${ }^{2}$ Corresponding author: richard.stockdale@dpi.vic.gov.au than that in milk, and took much longer to respond to change in Se status, but it was not affected by diet at any time either. For the on-farm production of Seenriched milk, it is important to be able to predict milk Se concentration from Se input. It seems that type of diet does not affect this relationship.

Key words: dietary selenium, milk selenium, dairy cow, type of diet

\section{INTRODUCTION}

Considerable research has recently been undertaken where dairy cows have been fed diets with between 2 and $134 \mathrm{mg}$ of Se/d (e.g., Palacios et al., 2005; Hoac et al., 2008; Juniper et al., 2008a; Ceballos et al., 2009). This has resulted in milk Se concentrations ranging from 7 to $551 \mu \mathrm{g}$ of Se/L or $\mathrm{kg}$. Much of this research has been concerned with producing milk or milk products for human consumption to help alleviate Se deficiencies, whereas some has been aimed at providing supranutritional Se levels for human health. Selenium enters the food chain when it is taken up from the soil and incorporated into plant protein, which is then used directly by humans or consumed by animals and incorporated into animal products. On reviewing the literature, Weiss (2003) and Ceballos et al. (2009) found that supplementing the diet of cows with an organic source of Se, such as Se yeast, was more effective at increasing the concentration of Se in milk than similar amounts of Se given in an inorganic form (e.g., sodium selenite or sodium selenate). Selenium in this form is absorbed with a high efficiency and is more effectively used and retained by the ruminant compared with absorption from an inorganic source of Se (e.g., Knowles et al., 1999), and it is safer to use. The bioavailability of an organic source of Se that has been incorporated into milk has also been shown to be greater than Se from other sources in pigs (McIntosh et al., 2008; Uglietta et al., 2008), and its efficacy in colorectal cancer prevention in mice is better (Hu et al., 2008). There 
is increasing interest from local Australian dairy companies in marketing high-Se products, particularly in the Asia region. These markets require products that are consistently high in Se, and the Se needs to be in a bioactive form. Currently, there are limitations to the amount of Se that is permitted to be fed to dairy cows in some regions of the world, but as human populations age, with an increasing number of people afflicted by cancers and other immune system issues, these restrictions may change.

It is already technically feasible to increase Se concentrations in milk to supply a significant amount of Se (e.g., Heard et al., 2007; Juniper et al., 2008a; Walker et al., 2010). To do this on a commercial scale, however, feeding systems must be developed that can provide specified concentrations of Se in milk. Although relationships between milk Se concentrations and Se intake are good within experiments, they often differ between experiments (e.g., Givens et al., 2004; Wang et al., 2009; Calamari et al., 2010). Heard et al. (2007) demonstrated that stage of lactation of Holstein-Friesian cows grazing pasture and fed concentrates did not affect this relationship, but some of the variation between experiments may be due to feed differences because diets have ranged from grazed pasture plus concentrates to TMR in intensive feeding systems. The role of the basal diet needs clarification because Koenig et al. (1997) found that Se absorption and retention were greater in sheep fed a concentrate-based diet than in those fed forage.

To determine whether diet might influence the relationship between Se concentration in milk and Se intake, with the Se principally being contributed by Se yeast, this study was undertaken in which cows were fed different amounts of pasture and concentrates or a TMR. It was hypothesized that the concentration of Se in milk would depend on the amount of Se consumed, regardless of the diet of the cows.

\section{MATERIALS AND METHODS}

All procedures were conducted using protocols approved by the Northern Victorian Animal Ethics Committee. The experiment was undertaken at the Victorian Department of Primary Industries' Kyabram Center $\left(36^{\circ} 20^{\prime} \mathrm{S}, 145^{\circ} 04^{\prime} \mathrm{E}\right)$ for $6 \mathrm{wk}$ in November/December 2006 using 70 multiparous Holstein-Friesian cows that were in mid-lactation. Cows were $78 \mathrm{~d}(\mathrm{SD} \pm 15.4)$ into lactation at the start of the experiment, and were producing $33.5( \pm 4.20) \mathrm{kg}$ of milk/d with milk fat, protein, and lactose concentrations of $3.7( \pm 0.52), 3.1( \pm 0.19)$, and $5.0( \pm 0.12) \%$, respectively. Their mean BW and BCS were $561( \pm 50.1) \mathrm{kg}$ and $4.3( \pm 0.42)$ units on the 8-point scale of Earle (1976), respectively, and they had an average SCC of $151,000 / \mathrm{mL}( \pm 368,400)$. Data were collected during the 2 wk before the experiment began for selection of cows and allocation to treatment, and for correction of data for between-cow variation. During this time, all cows grazed pasture, and were fed about $4 \mathrm{~kg}$ of DM of pelleted concentrates in the dairy at milking times.

\section{Experimental Design and Management}

Of the 70 cows, 60 grazed irrigated perennial pasture consisting of white clover (Trifolium repens L.), perennial ryegrass (Lolium perenne L.), and paspalum (Paspalum dilatatum Poir.) at allowances of either 20 or $40 \mathrm{~kg}$ of $\mathrm{DM} /$ cow per $\mathrm{d}$. These cows received 1 of 3 concentrate supplement treatments, either 1,3 , or $6 \mathrm{~kg}$ of $\mathrm{DM} /$ cow per d of pellets, and at each level of concentrate feeding, the pellets were formulated to provide 1 of 2 quantities of Se from Se yeast produced from Saccharomyces cerevisiae CNCM I-3060 (Sel-Plex; Alltech Biotechnology, Nicholasville, KY), either about 16 or $32 \mathrm{mg}$ of Se/d. There were 2 additional treatments where a TMR was fed to the remaining 10 cows. The TMR included corn silage, cereal-grain based pellets, canola meal, alfalfa hay, and a mineral mix (Table 1). The cows fed the TMR were also supplemented with 1 $\mathrm{kg}$ of $\mathrm{DM} / \mathrm{d}$ of pellets formulated to provide either of the 2 quantities of supplemental Se (these pellets were the same as those offered to the grazing cows that were fed $1 \mathrm{~kg}$ of pellets). Additionally, $0.25 \mathrm{~kg}$ of cereal-grain based pellets was fed to all cows at each milking to facilitate movement of cows into the milking shed. There were 5 cows per treatment.

Cows were allocated to treatments by stratified randomization based on milk yield, milk protein concentration, milk fat concentration, age, BCS, and BW before the experiment began using Baird's method (Baird, 1994) according to the ALLOCATE procedure in Genstat (Genstat 10, 2007; Lawes Agricultural Trust, Rothamsted, UK). All cows allocated to the low pasture allowance grazed as 1 group on irrigated perennial pasture, and the cows allocated to the high pasture allowance grazed as a separate group. Each paddock used during the experiment was subdivided by an electric fence to allow the 2 herds to graze sideby-side in that paddock, but at their allocated pasture allowances. The cows fed the TMR were fed as 1 group on a shaded concrete feeding strip adjacent to a rice hull loafing area. All cows were individually offered half of their Se-enriched pellets immediately following the a.m. milking, and the other half immediately following the p.m. milking. After being allowed sufficient time to consume their supplement, the pasture-fed cows returned to their paddock to graze and the TMR-fed cows returned to the feeding facility. 
Table 1. Composition and nutrient analysis of the TMR diet and selenium-enriched pelleted concentrates, and nutritive characteristics of the pasture

\begin{tabular}{|c|c|c|c|}
\hline Item & TMR & Pasture & $\begin{array}{l}\text { Selenium-enriched } \\
\text { pelleted concentrates }\end{array}$ \\
\hline $\mathrm{DM}(\%)$ & 60.6 & - & - \\
\hline \multicolumn{4}{|c|}{ Feed ingredients (\% of DM) } \\
\hline Corn silage & 42.1 & - & - \\
\hline Alfalfa hay & 14.6 & - & - \\
\hline Pelleted concentrates & 23.2 & - & - \\
\hline Cereal grain fines & - & - & 69.5 \\
\hline Canola meal & 19.3 & - & 11.8 \\
\hline Palm kernel meal & - & - & 10.0 \\
\hline Millrun & - & - & 2.4 \\
\hline Molasses & - & - & 1.0 \\
\hline Rice hulls & - & - & 0.9 \\
\hline Mineral mix & 0.8 & - & 4.4 \\
\hline \multicolumn{4}{|c|}{ Nutrient content (DM basis) } \\
\hline $\mathrm{ME}^{1}(\mathrm{MJ} / \mathrm{kg})$ & 11.3 & 10.7 & 12.7 \\
\hline $\mathrm{CP}(\%)$ & 17 & 16 & 14 \\
\hline $\operatorname{NDF}(\%)$ & 33 & 50 & 22 \\
\hline Calcium (\%) & 0.74 & 0.49 & 1.01 \\
\hline Phosphorus (\%) & 0.39 & 0.29 & 0.51 \\
\hline Potassium (\%) & 1.14 & 2.31 & 0.56 \\
\hline Sodium $(\%)$ & 0.15 & 0.42 & 0.55 \\
\hline Magnesium (\%) & 0.30 & 0.28 & 0.28 \\
\hline Chlorine (\%) & 0.48 & 1.48 & 0.46 \\
\hline Sulfur $(\%)$ & 0.24 & 0.25 & 0.16 \\
\hline Manganese $(\mathrm{mg} / \mathrm{kg})$ & 73 & 110 & 146 \\
\hline Copper $(\mathrm{mg} / \mathrm{kg})$ & 11 & 8 & 53 \\
\hline Zinc $(\mathrm{mg} / \mathrm{kg})$ & 49 & 28 & 200 \\
\hline Iron $(\mathrm{mg} / \mathrm{kg})$ & 244 & 430 & 165 \\
\hline
\end{tabular}

${ }^{1} \mathrm{ME}$ was estimated using $0.17 \times$ in vitro DM digestibility - 2.0 (Standing Committee on Agriculture, 1990).

After 6 wk of feeding Se-enriched pellets, treatments ceased and the cows returned to the research center herd where their milk and blood Se concentrations were monitored for a further 9 wk. During this time, the herd was fed a partial mixed ration of triticale hay, canola hay, corn silage, and pelleted concentrates, in addition to a minimal amount of dry pasture.

\section{Measurements}

Pasture height was measured on Monday (for the following $3 \mathrm{~d}$ ), and Thursday (for the following $4 \mathrm{~d}$ ) for the 6 wk of the experiment by taking up to 240 height readings using a rising plate meter (Earle and McGowan, 1979). Pre-grazing pasture mass was estimated using standard pasture height/pasture mass equations in a locally-generated dairy nutrition model, Diet Check (Heard et al., 2004b). Mean meter reading and pasture mass $( \pm \mathrm{SD})$ were $16.5( \pm 2.51) \mathrm{cm}$ and $5.9( \pm 0.59) \mathrm{t}$ of $\mathrm{DM} / \mathrm{ha}$, respectively. The area offered to each group of cows was calculated to provide their allotted pasture allowances. Cows were offered half of their daily pasture allowance after the a.m. milking and the remaining pasture after the p.m. milking. Pasture intakes of individual cows were estimated using the Diet Check nutrition model (Heard et al., 2004b).
Each week, a bulked pasture sample (collected on Monday and Thursday) representative of pasture consumed by cows was collected by cutting a minimum of 15 small quadrats at predetermined positions along a transect across the grazing area. Representative subsamples of approximately 100-g fresh weight were oven-dried at $60^{\circ} \mathrm{C}$ for $72 \mathrm{~h}$, ground through a 0.5 $\mathrm{mm}$ screen, and stored for subsequent analysis. Total $\mathrm{N}$ was determined by a LECO FP-428 autoanalyzer (LECO Corporation, St Joseph, MI), and CP content was calculated as $\mathrm{N} \times 6.25$. In vitro $\mathrm{DM}$ digestibility (IVDMD) was determined using the pepsin-cellulase methodology described by Clarke et al. (1982), and ME $(\mathrm{MJ} / \mathrm{kg}$ of $\mathrm{DM})$ was estimated using the equation 0.17 $\times$ IVDMD - 2.0 (Standing Committee on Agriculture, 1990). Neutral detergent fiber was determined using a modification of the method described by Van Soest et al. (1991), with the amylase step omitted because the samples filtered freely. Mineral analyses were carried out using inductively coupled plasma emission spectrometry.

The pellets offered to, and refused by, each cow were weighed daily, and samples were dried at $100^{\circ} \mathrm{C}$ for 24 $\mathrm{h}$ to determine DM content. Samples of pellets were collected each week throughout the experimental period, dried at $60^{\circ} \mathrm{C}$, ground, and analyzed for IVDMD 
using a rumen fluid-pepsin method (Tilley and Terry, 1963). Nitrogen, NDF, and mineral concentrations were determined as described above, except that the amylase step was retained when analyzing for NDF.

Daily DMI of the group of cows consuming the TMR was measured by weighing the feed offered and that refused each day, and taking samples to determine DM\% by drying at $100^{\circ} \mathrm{C}$ for at least $48 \mathrm{~h}$. Each week, bulked samples of the TMR were dried at $60^{\circ} \mathrm{C}$, ground, and analyzed for IVDMD, N, NDF, and mineral concentrations as described for pellets above.

Cows were milked at 0530 and $1545 \mathrm{~h}$ each day and individual milk yields were recorded at each milking for $2 \mathrm{wk}$ before the experiment began and throughout the treatment period. Aliquot samples of the milk from each cow were taken at a p.m. and a.m. milking before the experiment, each week during the experiment, and at 3,6, and 9 wk after the feeding of Se-enriched pellets had ceased. These samples were analyzed for fat, protein, and lactose concentrations, and SCC, by a Foss 4000/5000 Combi (Foss Electric, Hillerød, Denmark) and for total milk Se concentration after the p.m. and a.m. aliquots had been combined. Samples for Se analysis were stored at $-20^{\circ} \mathrm{C}$ before being analyzed. Cows were weighed, and their BCS assessed (Earle, 1976), before treatments commenced and each week thereafter for the duration of the treatment period.

Whole blood samples (about $10 \mathrm{~mL}$ ) were taken from the tail vein of each cow for analysis of blood Se concentration before the start of the experiment, during the experimental period (wk 3 and 6), and at 3, 6, and 9 wk after the withdrawal of feeding treatments. Samples were collected in the morning, after the cows had been fed their supplements, into an evacuated heparinized blood tube and immediately put on ice before being stored at $-80^{\circ} \mathrm{C}$ before analysis for Se concentration.

The concentration of total Se in all samples (feeds, milk, whole blood) was determined by inductively coupled plasma mass spectrometry/vapor generation following digestion of samples in a mixture of nitric and perchloric acids, as described by Heard et al. (2007).

\section{Statistical Analysis}

Analysis of variance was used to determine treatment responses, with the 12 treatments associated with grazed pasture being analyzed together, and the TMR treatments analyzed separately. Treatment responses of pasture-fed cows were analyzed by the repeated measures ANOVA procedure in Genstat 10 (2007; Lawes Agricultural Trust) in a $2 \times 2 \times 3$ factorial design, with daily pasture allowance (nominally 20 or $40 \mathrm{~kg}$ of DM/ cow), amount of Se in pellets (nominally 16 or $32 \mathrm{mg}$ of $\mathrm{Se} / \mathrm{d})$, and weight of pellets $(1,3$, or $6 \mathrm{~kg}$ of $\mathrm{DM} / \mathrm{cow}$ per d) as the factors. For each variable analyzed, the data were covariately adjusted using the related information collected before the imposition of treatments. Repeated measures of the data from the TMR animals were analyzed separately for each time by simple analysis of covariance (amount of Se in pellets; nominally 16 or $32 \mathrm{mg}$ of Se/d) because the small number of animals limited the use of the repeated measures facility in Genstat. A cow was the experimental unit.

Relationships between milk or blood Se concentration $(Y ; \mu \mathrm{g} / \mathrm{kg})$ and total estimated Se intake $(X ; \mathrm{mg} / \mathrm{d})$ were examined by using group data in stepwise regression analyses in Genstat 10 according to the following model:

$$
\begin{aligned}
Y=a+ & b \times X+c \times X^{2}+d \times \operatorname{diet} \\
+ & e \times \text { interaction, }
\end{aligned}
$$

where $a, b, c, d$, and $e$ are all coefficients, diet $=\mathrm{a}$ pseudovariable to distinguish between the pasture-fed $(+1)$ and TMR-fed $(-1)$ cows, and interaction $=$ the first-order interaction between $X$ and diet. A variable was only included in a regression if it was significant at $P<0.05$. For milk Se, average steady-state data during the treatment period, defined as being for the last $5 \mathrm{wk}$ of the experimental period, were used, whereas the 2 blood sampling times during treatment were analyzed separately.

\section{RESULTS}

\section{Feeds and Intake}

Nutritive characteristics of the feeds offered to the cows in the study are given in Table 1 . The estimated DMI of pasture by cows averaged 11.4 and $15.3 \mathrm{~kg} /$ cow in the low and high allowance groups, with variation around these averages (Table 2) being due to the different amounts of supplement consumed. The cows in the TMR treatments had an average daily DMI of 24.8 (day-to-day $\mathrm{SD} \pm 1.27$ ) $\mathrm{kg} /$ cow, exclusive of their intake of Se yeast pellets. The DM content of the TMR was $61 \%$, and refusals averaged $7.5 \%$ of that offered each day. Average measured DMI of pellets are given in Table 2, with intakes stabilizing by about $\mathrm{d} 7$ of the study in all treatments.

Concentrations of Se in the various feeds consumed by cows in all treatments are given in Table 2 . Where the nominal provision of Se yeast in pellets was 16 $\mathrm{mg} / \mathrm{d}$, the measured amount of Se offered in the 1, 3 , and $6 \mathrm{~kg}$ of DM of pellets was 15.3, 18.3, and 13.6 $\mathrm{mg}$, respectively, and in the $32-\mathrm{mg}$ pellets, it was 24.7 , 32.1 , and $36.7 \mathrm{mg}$ of Se, respectively. Total Se intakes 
Table 2. Estimated daily DM and selenium intakes for all treatments averaged across the whole experimental period 兽

\begin{tabular}{|c|c|c|c|c|c|c|c|c|c|c|c|c|c|c|}
\hline \multirow[b]{3}{*}{ Item } & \multicolumn{12}{|c|}{ Pasture treatment $^{1}$} & & \\
\hline & \multicolumn{6}{|c|}{$20 \mathrm{~kg}$ of $\mathrm{DM} /$ cow per $\mathrm{d}$} & \multicolumn{6}{|c|}{$40 \mathrm{~kg}$ of $\mathrm{DM} /$ cow per $\mathrm{d}$} & \multicolumn{2}{|c|}{ TMR treatment $^{2}$} \\
\hline & $1+16$ & $1+32$ & $3+16$ & $3+32$ & $6+16$ & $6+32$ & $1+16$ & $1+32$ & $3+16$ & $3+32$ & $6+16$ & $6+32$ & $1+16$ & $1+32$ \\
\hline \multicolumn{15}{|l|}{ DM intake $(\mathrm{kg} / \mathrm{cow})$} \\
\hline Pasture/TMR & 12.5 & 12.4 & 11.5 & 11.7 & 10.1 & 10.0 & 16.1 & 16.8 & 15.6 & 15.5 & 13.4 & 14.2 & 24.6 & 24.2 \\
\hline Se pellets & 1.01 & 1.00 & 3.00 & 2.98 & 5.76 & 5.90 & 0.99 & 0.96 & 2.94 & 2.98 & 5.75 & 5.56 & 0.77 & 0.85 \\
\hline Dairy pellets & 0.4 & 0.4 & 0.4 & 0.4 & 0.4 & 0.4 & 0.4 & 0.4 & 0.4 & 0.4 & 0.4 & 0.4 & 0.4 & 0.4 \\
\hline Total DMI & 13.9 & 13.9 & 14.9 & 15.1 & 16.3 & 16.3 & 17.5 & 18.2 & 18.9 & 18.9 & 19.6 & 20.1 & 25.8 & 25.5 \\
\hline \multicolumn{15}{|l|}{$\begin{array}{l}\text { Se concentration } \\
\text { (mg/kg of DM) }\end{array}$} \\
\hline Pasture/TMR & $\begin{array}{c}0.12 \\
(0.042)\end{array}$ & 0.12 & 0.12 & 0.12 & 0.12 & 0.12 & $\begin{array}{c}0.12 \\
(0.042)\end{array}$ & 0.12 & 0.12 & 0.12 & 0.12 & 0.12 & $\begin{array}{c}0.23 \\
(0.019)\end{array}$ & 0.23 \\
\hline Se pellets & $\begin{array}{l}15.32 \\
(0.726)\end{array}$ & $\begin{array}{l}24.74 \\
(1.579)\end{array}$ & $\begin{array}{l}6.11 \\
(0.741)\end{array}$ & $\begin{array}{l}10.69 \\
(0.942)\end{array}$ & $\begin{array}{c}2.27 \\
(0.403)\end{array}$ & $\begin{array}{l}6.12 \\
(0.361)\end{array}$ & 15.32 & 24.74 & 6.11 & 10.69 & 2.27 & 6.12 & 15.32 & 24.74 \\
\hline Dairy pellets & $\begin{array}{l}0.47 \\
(0.076)\end{array}$ & 0.47 & 0.47 & 0.47 & 0.47 & 0.47 & 0.47 & 0.47 & 0.47 & 0.47 & 0.47 & 0.47 & 0.47 & 0.47 \\
\hline \multicolumn{15}{|l|}{ Se intake (mg/cow) } \\
\hline Pasture/TMR & 1.50 & 1.49 & 1.38 & 1.40 & 1.21 & 1.21 & 1.93 & 2.02 & 1.87 & 1.86 & 1.61 & 1.70 & 5.66 & 5.57 \\
\hline Se pellets & 15.47 & 24.74 & 18.33 & 31.86 & 13.08 & 36.11 & 15.17 & 23.75 & 17.96 & 31.86 & 13.05 & 34.03 & 11.80 & 20.78 \\
\hline Dairy pellets & 0.19 & 0.19 & 0.19 & 0.19 & 0.19 & 0.19 & 0.19 & 0.19 & 0.19 & 0.19 & 0.19 & 0.19 & 0.19 & 0.19 \\
\hline Total Se intake & 17.16 & 26.42 & 19.90 & 33.45 & 14.48 & 37.51 & 17.29 & 25.96 & 20.02 & 33.91 & 14.85 & 35.92 & 17.65 & 26.54 \\
\hline$\%$ from Se pellets & 90 & 94 & 92 & 95 & 90 & 96 & 88 & 91 & 90 & 94 & 88 & 95 & 66 & 78 \\
\hline
\end{tabular}

${ }^{1}$ Base feed $=$ pasture allowance of 20 or $40 \mathrm{~kg}$ of DM/cow per day; concentrates for all treatments are shown in the form $\mathrm{x}+\mathrm{y}, \mathrm{where} \mathrm{x}=\mathrm{kg}$ of DM/cow per $\mathrm{d}$ and $\mathrm{y}=\mathrm{mg}$ of Se from Sel-Plex (Alltech Biotechnology, Nicholasville, KY).

${ }^{2}$ TMR treatments, with $1 \mathrm{~kg}$ of DM/cow per d of concentrates nominally carrying either 16 or $32 \mathrm{mg}$ of Se from Se yeast (Sel-Plex).

${ }^{3}$ Standard deviations are given in parentheses. 
ranged from 14.5 to $35.9 \mathrm{mg} / \mathrm{d}$, and of this, the Seenriched pellets provided 93, 91, and $72 \%$ for the cows allocated 20 and $40 \mathrm{~kg}$ of pasture $\mathrm{DM} / \mathrm{d}$ or the TMR, respectively (Table 2 ).

\section{Animal Production}

No interactions were found between time and any aspect of diet for milk production during the experimental period after the first week, when cows were adjusting to diets; therefore, only summary statistics for the last $5 \mathrm{wk}$ are presented for animal production variables (Table 3). Average daily milk yield ranged from 22 to $40 \mathrm{~kg} / \mathrm{cow}$, with ranges in milk fat, protein, and lactose concentrations of 2.4 to $4.1 \%, 2.8$ to $3.2 \%$, and 4.8 to $5.2 \%$, respectively. The TMR-fed cows produced more milk than any of the pasture-fed cows, and this milk was lowest in milk fat concentration, toward the top of the range in protein concentration, and highest in lactose concentration (Table 3). No effects of amount of Se yeast on any milk production variable or on SCC, $\mathrm{BW}$, and BCS, for either the pasture-fed or TMR-fed cows were noted.

\section{Selenium Concentrations in Milk and Blood}

Pre-experimental concentrations of Se in milk averaged $15 \mu \mathrm{g} / \mathrm{kg}$ (Table 4). With the introduction of treatments, milk Se concentrations responded quickly, reaching $89 \%$ of steady-state levels, on average, at d 5 . Milk Se concentrations had declined to about double pretreatment levels by 3 wk after treatments had ceased, but there was little further change in the ensuing $6 \mathrm{wk}$. For the pasture-fed cows, pasture allowance, amount of concentrates, and amount of Se yeast all significantly affected milk Se concentration during the treatment period, in line with intakes of DM and Se. Similar trends with amount of Se yeast were evident in the TMR-fed cows (Table 4).

The regression equation relating total Se intake $(\mathrm{mg} / \mathrm{d})$ and milk Se concentration $(\mu \mathrm{g} / \mathrm{kg})$ using steady-state data (d 12 to 40) was:

$$
\begin{gathered}
\text { milk } \mathrm{Se}=11.0( \pm 6.21)+4.99( \pm 0.242) \\
\text { total Se intake, } \\
\mathrm{R}^{2}=0.97(P<0.001) ; \mathrm{RSD}=7.1 ; \\
\mathrm{CV}=5.4 \% ; \text { and } \mathrm{n}=14
\end{gathered}
$$

Each $1 \mathrm{mg}$ of Se eaten increased the Se concentration of milk by $5 \mu \mathrm{g} / \mathrm{kg}$, and this response was not affected by the diet of the cows (Figure 1a).

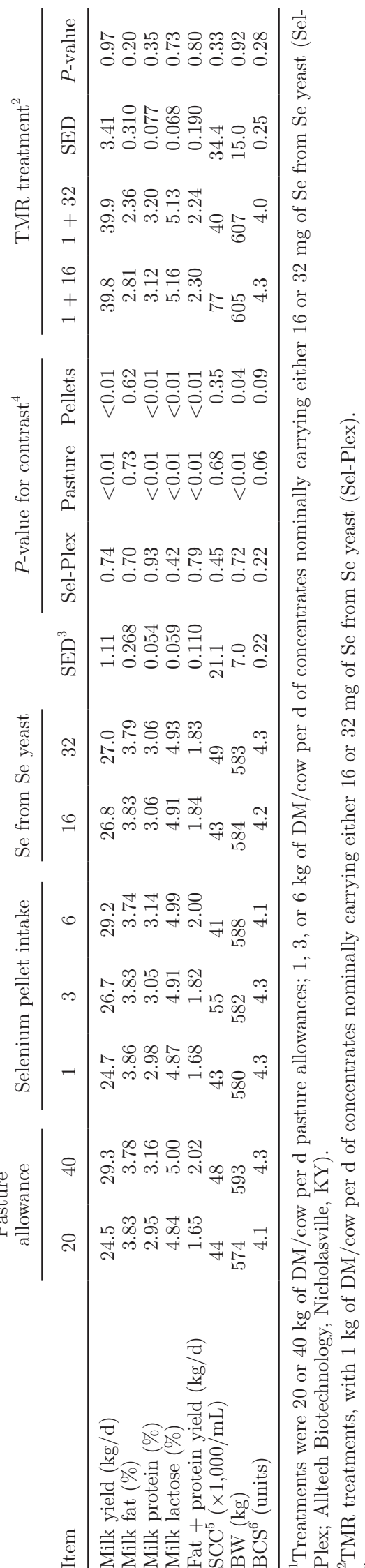


Table 4. Selenium concentrations in milk and blood before the experiment, during the experimental period (to $42 \mathrm{~d}$ ), and for 9 wk after the feeding of selenium-enriched pellets had ceased

\begin{tabular}{|c|c|c|c|c|c|c|c|c|c|c|c|c|c|c|c|}
\hline \multirow[b]{3}{*}{ Se concentration $(\mu \mathrm{g} / \mathrm{kg})$} & \multicolumn{11}{|c|}{ Pasture treatment $^{1}$} & & & & \\
\hline & \multicolumn{2}{|c|}{ Pasture allowance } & \multicolumn{3}{|c|}{ Selenium pellet intake } & \multicolumn{2}{|c|}{ Se from Se yeast } & \multirow[b]{2}{*}{$\mathrm{SED}^{3}$} & \multicolumn{3}{|c|}{$P$-value for contrast ${ }^{4}$} & \multicolumn{4}{|c|}{ TMR treatment $^{2}$} \\
\hline & 20 & 40 & 1 & 3 & 6 & 16 & 32 & & Sel-Plex & Pasture & Pellets & $1+16$ & $1+32$ & SED & $P$-value \\
\hline \multicolumn{16}{|l|}{ In milk } \\
\hline Pre-experimental & 15 & 15 & 15 & 15 & 15 & 15 & 15 & - & - & - & - & 13 & 14 & - & - \\
\hline d 5 & 131 & 116 & 110 & 134 & 128 & 90 & 158 & 8.5 & $<0.01$ & 0.01 & $<0.01$ & 75 & 121 & 19.6 & 0.04 \\
\hline d $12-40$ & 145 & 131 & 126 & 146 & 143 & 100 & 176 & & & & & 91 & 137 & 22.5 & 0.08 \\
\hline d 62 & 29 & 27 & 27 & 28 & 28 & 26 & 30 & & & & & 24 & 27 & 2.3 & 0.26 \\
\hline d 82 & 25 & 23 & 23 & 24 & 25 & 23 & 25 & & & & & 22 & 23 & 1.4 & 0.51 \\
\hline d 104 & 26 & 24 & 24 & 25 & 27 & 24 & 26 & & & & & 23 & 24 & 1.4 & 0.51 \\
\hline \multicolumn{16}{|l|}{ In whole blood } \\
\hline Pre-experimental & 116 & 122 & 123 & 117 & 117 & 119 & 119 & - & - & - & - & 104 & 108 & - & - \\
\hline d 21 & 202 & 204 & 196 & 209 & 203 & 179 & 226 & 12.8 & $<0.01$ & 0.03 & $<0.01$ & 187 & 214 & 20.3 & 0.26 \\
\hline d 42 & 250 & 258 & 237 & 263 & 262 & 218 & 290 & & & & & 238 & 276 & 31.7 & 0.26 \\
\hline d 63 & 208 & 222 & 198 & 220 & 227 & 192 & 238 & & & & & 213 & 250 & 24.5 & 0.17 \\
\hline d 83 & 203 & 219 & 196 & 215 & 222 & 193 & 229 & & & & & 212 & 246 & 24.2 & 0.20 \\
\hline d 105 & 201 & 211 & 193 & 206 & 218 & 189 & 222 & & & & & 209 & 233 & 22.6 & 0.33 \\
\hline
\end{tabular}

${ }^{1}$ Treatments were 20 or $40 \mathrm{~kg}$ of DM/cow per d pasture allowances; 1, 3, or $6 \mathrm{~kg}$ of DM/cow per d of concentrates nominally carrying either 16 or $32 \mathrm{mg}$ of Se from Se yeast (SelPlex; Alltech Biotechnology, Nicholasville, KY)

${ }^{2} \mathrm{TMR}$ treatments, with $1 \mathrm{~kg}$ of DM/cow per d of concentrates nominally carrying either 16 or $32 \mathrm{mg}$ of Se from Se yeast (Sel-Plex).

${ }^{3}$ Standard error of difference.

${ }^{4} P$-values for contrasts for grazing cows; Sel-Plex: 16 vs. $32 \mathrm{mg}$ of Se from Sel-Plex; Pasture: 20 vs. $40 \mathrm{~kg}$ of DM/cow per d pasture allowances; Pellets: 1 vs. 3 vs. 6 kg of DM/cow per $\mathrm{d}$ of pellets. These cover all times because of repeated measures analysis, and no significant interactions with time were found. 

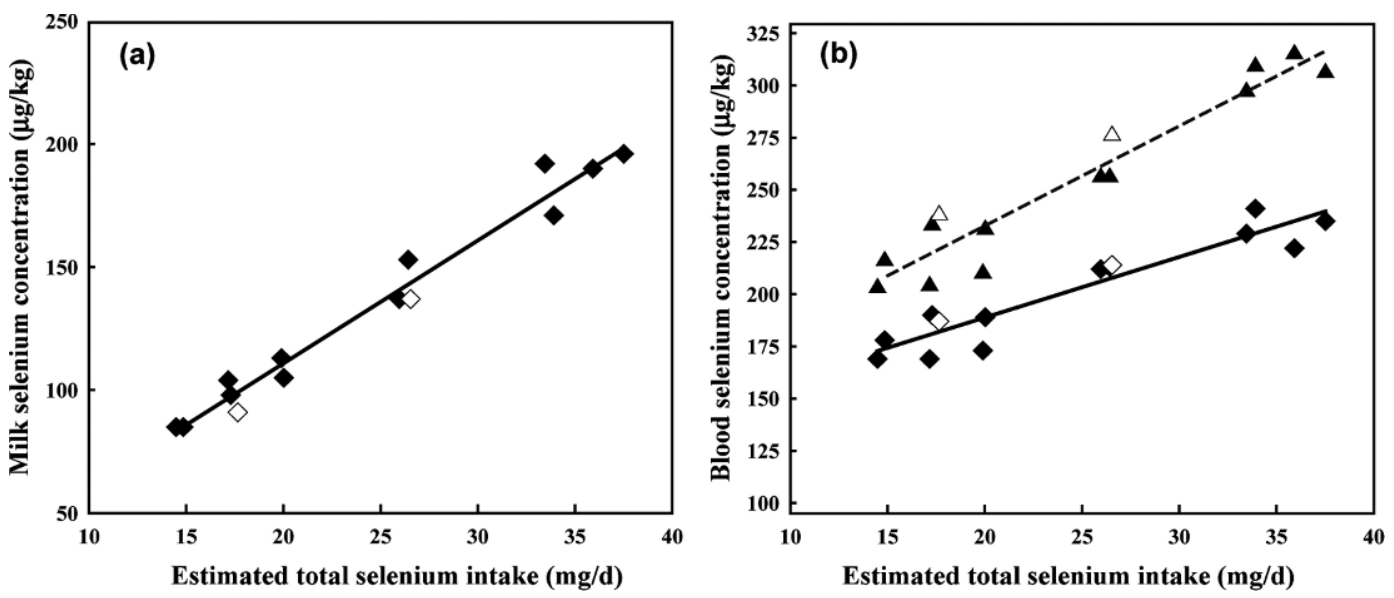

Figure 1. Relationships between total Se intake and a) milk (average of d 12 to 40) and b) blood (full line = after 3 wk of supplementation; broken line $=$ after $6 \mathrm{wk}$ of supplementation) Se concentrations in cows grazing pasture and fed concentrates $(\bullet, \mathbf{\Delta})$ or a TMR $(\diamond, \Delta)$.

Pre-experimental concentrations of Se in whole blood averaged $117 \mu \mathrm{g} / \mathrm{kg}$, and responded more slowly than milk Se concentration to change in dietary Se intake (Table 4). After the feeding treatments ceased, Se concentrations were lower than at the end of treatment, but they were still almost 100\% higher than those before Se supplementation commenced. For the pasture-fed cows, pasture allowance, weight of pellets, and amount of Se yeast were all significantly associated with blood Se concentration, whereas similar, but nonsignificant, trends with the inclusion of Se yeast were evident in the TMR-fed cows (Table 4). As found for milk Se concentration, blood Se concentration $(\mu \mathrm{g} / \mathrm{kg})$ was primarily influenced by total Se intake $(\mathrm{mg} / \mathrm{d})$, as described by the following regression equations generated from the data presented in Figure 1b:

$$
\begin{gathered}
\text { blood Se at wk } 3=130( \pm 7.7)+2.90 \\
( \pm 0.302) \text { total Se intake, } \\
\mathrm{R}^{2}=0.89(P<0.001) ; \mathrm{RSD}=8.9 ; \mathrm{CV}= \\
4.4 \% ; \text { and } \mathrm{n}=14, \text { and }
\end{gathered}
$$$$
\text { blood Se at wk } 6=137( \pm 10.4)+4.78
$$$$
( \pm 0.407) \text { total Se intake, }
$$$$
\begin{aligned}
\mathrm{R}^{2}= & 0.92(P<0.001) ; \mathrm{RSD}=12.0 \\
& \mathrm{CV}=4.7 \% ; \text { and } \mathrm{n}=14
\end{aligned}
$$

These responses were not affected by diet, but at 6 wk, there was a trend $(P=0.063)$ for blood Se concentrations to be greater with the TMR.

\section{DISCUSSION}

The most important result from this study was that Se intake, principally from Se yeast, was a very good predictor of Se concentration in milk $\left(\mathrm{R}^{2}=0.97\right)$, thereby supporting our hypothesis that the concentration of Se in milk would depend on the amount of Se consumed regardless of the type of diet or the resulting milk yield of the cows, and in spite of there being limited data for the TMR diet. The diets used here covered the range of feeding systems likely to be encountered on farms in Australia, and it is really only the quantity of Se that would differ because farmers would only offer enough Se to provide for the dietary requirements of their animals. Milk yields varied greatly between treatments, but the response from pasture-fed cows and TMR-fed cows were similar even though Se yeast supplied more than $90 \%$ of dietary Se in the pasture-concentrate diets and only about $72 \%$ with TMR.

The response in milk Se concentration found here, of $5 \mu \mathrm{g} / \mathrm{kg}$ for each $1 \mathrm{mg}$ of Se consumed, was quite different from that found by Heard et al. (2007) and Walker et al. (2010), who together reported a response of $7 \mu \mathrm{g}$ of Se $/ \mathrm{kg}$ of milk for each mg of Se consumed, up to a total of $42 \mathrm{mg}$ of Se/d. Each set of data was collected under similar conditions at Kyabram, and the Se analyses were conducted at the same laboratory using the same technique. A key difference between experiments, however, was that the Se-enhanced pellets used in the current experiment were manufactured at a commercial pelleting plant, whereas the pellets used by Heard et al. (2007) were produced under less severe conditions in a research facility and Walker et al. (2010) introduced Se yeast directly into the rumen through rumen fistulae. It was postulated that the heat and pressure associated with the commercial pelleting process may have affected 
the bioavailability of Se from the Se yeast in our case, but a subsequent study by Stockdale and Gill (2010) suggested that this was unlikely; thus, an explanation for the different milk Se responses is not clear.

The other important result from this study was that blood Se concentration was slow to react to both the inclusion and exclusion of Se-enriched pellets in the diet of the cows. This response confirmed results from the study of Heard et al. (2007) in which blood Se was monitored for 3 wk after 6 wk of Se supplementation. Selenium is incorporated into red blood cells only during erythropoiesis, and because this process occurs slowly, there is a lag in blood Se responses following an increase in Se supplementation (Thompson et al., 1980). Juniper et al. (2008b) estimated that asymptotic values of blood Se in beef cattle were not likely to occur until about $150 \mathrm{~d}$ after the start of exposure to Se supplementation, reflecting the average lifespan of erythrocytes. Conversely, after the withdrawal of supplementation, the decline in blood Se concentrations will depend on erythrocyte turnover and the rate of release of Se from tissue reserves. Together, these processes account for the continued maintenance of milk Se concentrations above pre-experimental levels after Se supplementation had ceased. Body tissues store considerable quantities of organic Se, and Lee et al. $(2006,2007)$ recently reported high correlations between blood Se concentration and the concentration of Se in leg muscle and liver in steers offered supplements containing Se from Seenriched organic sources. Heard et al. (2007) have also shown a strong association between whole blood and muscle Se concentrations in lactating dairy cows. In both instances, however, daily Se intakes tended to be lower than those found here, up to about $8 \mathrm{mg} / \mathrm{d}$ in the research of Lee et al. (2006, 2007), and up to about 18 $\mathrm{mg} / \mathrm{d}$ in the case of Heard et al. (2007). It is suggested that the stores of Se in body tissue could continue to re-enter the blood stream for a considerable time after supplementation with large amounts of Se has ceased, but the length of time for which elevated blood, and therefore, milk, Se concentrations are likely to remain is currently unknown.

As in most research conducted recently where Se yeast has been fed for short periods (e.g., Heard et al., 2004a, 2007; Juniper et al., 2006, 2008a), dairy cow milk production was not affected by the amount of Se consumed. Although Harrison et al. (2006) reported an increase in milk protein when using Se yeast, it is principally when Se supplements are fed to Se-deficient cows that milk production responses can be expected. A blood Se concentration greater than $21 \mu \mathrm{g} / \mathrm{kg}$, which is associated with a milk Se concentration of $4 \mu \mathrm{g} /$ $\mathrm{kg}$ (Grace et al., 2001), is generally considered to be indicative of adequate Se in lactating dairy cows (Wich- tel et al., 1994; Thompson et al., 1998; Grace et al., 2001). Before the commencement of the present study, the mean milk and blood Se concentrations were 15 and $117 \mu \mathrm{g} / \mathrm{kg}$, respectively.

Differences existed in milk production associated with pasture allowance, amount of concentrates fed, and type of basal diet. The responses to pasture allowance and concentrate feeding seen in this study were typical of those recorded previously under irrigation in the northern Victorian region (Wales et al., 1999, 2006). The difference in production between the cows well fed on pasture plus concentrates and the cows offered TMR is also similar to that reported by Kolver and Muller (1998). Thus, the production responses of the cows in this study were not different from expectations.

Supranutritional quantities of Se for the prevention of human health conditions associated with reduced immunity may be 3 to 4 times higher than daily recommended intakes (150-200 $\mu \mathrm{g}$ of Se/d; McIntosh et al., 2008). To consume such quantities of Se, foods or ingredients must have high Se concentrations. Fish and brazil nuts are recognized as naturally high-Se foods, and McIntosh et al. (2008) have recently reported that a milk protein concentrate product, Tatura-Bio Se (Tatura Milk Industries, Tatura, Victoria, Australia), is a dairy source with high bioavailability and bioefficacy for disease prevention (e.g., for colorectal cancer; Hu et al., 2008). To provide the milk to manufacture the milk protein product, large amounts of Se must be fed to cows, and research has shown that the transfer of Se into milk is greater from organic sources of Se than from inorganic sources (Weiss, 2003; Ceballos et al., 2009). Selenium yeast is one such organic source, and $\mathrm{Hu}$ et al. (2008) have demonstrated that the efficacy of the milk protein concentrate for the prevention of colorectal cancer is much greater than that of the parent Se yeast. The quantities of supplemental Se needed to be fed to cows to provide the concentrations of milk Se required for such dairy products (e.g., in excess of $50 \mathrm{mg} / \mathrm{d}$ ) are not universally permitted (e.g., in the US, the FDA regulations limit Se supplementation of dairy cows to $0.3 \mathrm{mg} / \mathrm{kg}$ of $\mathrm{DM}$ ), but some regions have daily recommendations rather than legislation against specific amounts. Therefore, these countries have the opportunity to take advantage of potential increases in consumer demand for high-Se milk protein products for the enhancement of human health, and the results presented here would help in developing the on-farm strategies to significantly increase milk Se concentrations to meet product requirements.

\section{CONCLUSIONS}

Selenium intake was a very good predictor of Se concentration in milk in this instance, and the diet of the 
cows, or their level of milk production, did not seem to influence the Se intake/Se concentration relationship. Although milk Se concentration changed rapidly in response to changes in the amount of Se consumed, blood Se concentrations were much slower to react to both the inclusion and the exclusion of Se-enriched pellets in the diet of the cows, and after cessation of Se supplementation, this helped to maintain milk Se at higher concentrations than might otherwise be encountered. The apparent lack of effect of diet on milk Se concentration suggests that feeding systems can be developed in which milk is produced with predictably consistent Se concentrations to enable processing into Se-rich products if the demand emerges for human health products.

\section{ACKNOWLEDGMENTS}

Funding was provided by Tatura Milk Industries Pty Ltd (Tatura, Victoria, Australia), Alltech Biotechnology P/L (Dandenong South, Victoria, Australia), the Geoffrey Gardiner Dairy Foundation (Melbourne, Victoria, Australia) and the Victorian Department of Primary Industries (DPI). Tim Harrington of Ridley Agriproducts ( Pakenham, Victoria, Australia) assisted with formulation of the Se-enriched pellets. Valuable technical assistance was provided by Marg Jenkin, Stuart Austin, Daryl Wilson, Shelly Warde, and Allan Thorson of the Victorian Department of Primary Industries and the farm staff at DPI Kyabram. Biometrics support was provided by Sorn Norng.

\section{REFERENCES}

Baird, D. B. 1994. The design of experiments with covariates. PhD Thesis, University of Otago, New Zealand.

Calamari, L., F. Petrera, and G. Bertin. 2010. Effects of either sodium selenite or Se yeast (Sc CNCM 1-3060) supplementation on selenium status and milk characteristics in dairy cows. Livest. Sci. 128:154-165.

Ceballos, A., J. Sánchez, H. Stryhn, J. B. Montgomery, H. W. Barkema, and J. J. Wichtel. 2009. Meta-analysis of the effect of oral selenium supplementation on milk selenium concentration in cattle. J. Dairy Sci. 92:324-342.

Clarke, T., P. C. Flinn, and A. A. McGowan. 1982. Low-cost pepsincellulase assays for prediction of digestibility of herbage. Grass Forage Sci. 37:147-150.

Earle, D. F. 1976. A guide to scoring dairy cow condition. J. Agric. (Vic.) $74: 228-231$.

Earle, D. F., and A. A. McGowan. 1979. Evaluation and calibration of an automated rising plate meter for estimating dry matter yield of pasture. Aust. J. Exp. Agric. Anim. Husb. 19:337-343.

Givens, D. I., R. Allison, B. Cottrill, and J. S. Blake. 2004. Enhancing selenium content of bovine milk through alteration of the form and concentration of selenium in the diet of dairy cows. J. Sci. Food Agric. 84:811-817.

Grace, N. D., K. Ankenbauer-Perkins, A. M. Alexander, and R. M. Marchant. 2001. Relationship between blood selenium concentration or glutathione peroxidase activity, and milk selenium concentrations in New Zealand dairy cows. N. Z. Vet. J. 49:24-28.
Harrison, A., J. K. Margerison, and D. Wilde. 2006. Effect of source and level of selenium supplementation in the diets of lactating dairy cows on the selenium content of milk and cheese. Page 65 in Proc. Brit. Soc. Anim. Sci. British Society of Animal Science, Penicuik, Scotland.

Heard, J. W., G. P. Walker, P. J. Royle, G. H. McIntosh, and P. T. Doyle. 2004a. Effects of short-term supplementation with selenised yeast on milk production and composition of lactating cows. Aust. J. Dairy Technol. 59:199-203.

Heard, J. W., D. C. Cohen, P. T. Doyle, W. J. Wales, and C. R. Stockdale. 2004b. Diet Check-A tactical decision support tool for feeding decisions with grazing dairy cows. Anim. Feed Sci. Technol. 112:177-194.

Heard, J. W., C. R. Stockdale, G. P. Walker, C. M. Leddin, F. R. Dunshea, G. H. McIntosh, P. M. Shields, A. McKenna, G. P. Young, and P. T. Doyle. 2007. Increasing selenium concentration in milk: Effects of amount of selenium from yeast and cereal grain supplements. J. Dairy Sci. 90:4117-4127.

Hoac, T., J. Stagsted, T. Lundh, J. H. Nielsen, and B. Åkesson. 2008. Short-term effects of selenium supplementation of cows' feed on the content and distribution of selenium, copper and zinc in bovine milk, whey and blood plasma. J. Dairy Res. 75:326-334.

Hu, Y., G. H. McIntosh, R. K. Le Leu, R. Woodman, and G. P. Young. 2008. Suppression of colon oncogenesis by selenium-enriched milk proteins: Apoptosis and K-ras mutations. Cancer Res. 68:49364944.

Juniper, D. T., R. H. Phipps, D. I. Givens, A. K. Jones, C. Green, and G. Bertin. 2008a. Tolerance of ruminant animals to high dose in-feed administration of a selenium enriched yeast. J. Anim. Sci. 86:197-204.

Juniper, D. T., R. H. Phipps, A. K. Jones, and G. Bertin. 2006. Selenium supplementation of lactating cows: Effect on selenium concentration in blood, milk, urine, and feces. J. Dairy Sci. 89:35443551 .

Juniper, D. T., R. H. Phipps, E. Ramos-Morales, and G. Bertin. 2008b. Effect of dietary supplementation with selenium-enriched yeast or sodium selenite on selenium tissue distribution and meat quality in beef cattle. J. Anim. Sci. 86:3100-3109.

Knowles, S. O., N. D. Grace, K. Wurms, and J. Lee. 1999. Significance of amount and form of dietary selenium on blood, milk, and casein selenium concentrations in grazing dairy cows. J. Dairy Sci. 82:429-437.

Koenig, K. M., L. M. Rode, R. D. H. Cohen, and W. T. Buckley. 1997. Effects of diet and chemical form of selenium on selenium metabolism in sheep. J. Anim. Sci. 75:817-827.

Kolver, E. S., and L. D. Muller. 1998. Performance and nutrient intake of high producing Holstein cows consuming pasture or a total mixed ration. J. Dairy Sci. 81:1403-1411.

Lee, S. H., B. Y. Park, S. S. Lee, N. J. Choi, J. H. Lee, J. M. Yeo, J. K. Ha, W. J. Maeng, and W. Y. Kim. 2006. Effects of spent composts of selenium-enriched mushroom and sodium selenite on plasma glutathione peroxidase activity and selenium deposition in finishing Hanwoo steers. Asian-australas. J. Anim. Sci. 19:984-991.

Lee, S. H., B. Y. Park, J. M. Yeo, S. S. Lee, J. H. Lee, J. K. Ha, and W. Y. Kim. 2007. Effects of different selenium sources on performance, carcass characteristics, plasma glutathione peroxidase activity and selenium deposition in finishing Hanwoo steers. Asian-australas. J. Anim. Sci. 20:229-236.

McIntosh, G., F. Dunshea, T. McKenna, G. Walker, Y. Hu, J. Heard, R. Stockdale, M. Shields, G. Young, and P. Doyle. 2008. A dairy source of organic selenium for health and wellbeing. Food Aust. 60:132-134.

Palacios, O., J. R. Encinar, G. Bertin, and R. Lobinski. 2005. Analysis of the selenium species distribution in cow blood by size exclusion liquid chromatography-inductively coupled plasma collision cell mass spectrometry (SEC-ICPccMS). Anal. Bioanal. Chem. 383:516-522.

Standing Committee on Agriculture. 1990. Feeding standards for Australian livestock. CSIRO Publications, Melbourne, Australia.

Stockdale, C. R., and H. S. Gill. 2010. Effect of pelleting of concentrates on milk and blood selenium concentrations in lactating 
dairy cows when selenised yeast is included in the diet. Anim. Prod. Sci. 50:371-375.

Thompson, J. C., R. N. Thornton, S. N. Bruere, and R. S. Ellison. 1998. Selenium reference ranges in New Zealand cattle. N. Z. Vet. J. $46: 65-67$

Thompson, K. G., A. J. Fraser, B. M. Harrop, and J. A. Kirk. 1980. Glutathione peroxidase activity in bovine serum and erythrocytes in relation to selenium concentrations in blood, serum and liver. Res. Vet. Sci. 28:321-324.

Tilley, J. M. A., and R. A. Terry. 1963. A two-stage technique for the in vitro digestion of forage crops. J. Br. Grassl. Soc. 18:104-111.

Uglietta, R., P. T. Doyle, G. P. Walker, J. W. Heard, C. M. Leddin, C. R. Stockdale, G. H. McIntosh, G. P. Young, H. S. Gill, and F. R. Dunshea. 2008. Bioavailability of selenium from selenium-enriched milk assessed in the artificially-reared neonatal pig. Nutr. Dietetics 65(Suppl. 3):S37-S40.

Van Soest, P. J., J. B. Robertson, and B. A. Lewis. 1991. Methods for dietary fiber, neutral detergent fiber, and nonstarch polysaccharides in relation to animal nutrition. J. Dairy Sci. 74:3583-3597.

Wales, W. J., P. T. Doyle, C. R. Stockdale, and D. W. Dellow. 1999 Effects of variations in herbage mass, allowance and level of supplement on nutrient intake and milk production of dairy cows in spring and summer. Aust. J. Exp. Agric. 39:119-130.
Wales, W. J., J. W. Heard, C. K. M. Ho, C. M. Leddin, C. R. Stockdale, G. P. Walker, and P. T. Doyle. 2006. Profitable feeding of dairy cows on irrigated dairy farms in northern Victoria. Aust. J. Exp. Agric. 46:743-752.

Walker, G. P., F. R. Dunshea, J. W. Heard, C. R. Stockdale, and P. T. Doyle. 2010. Output of selenium in milk, urine and feces is proportional to selenium intake in dairy cows fed a total mixed ration supplemented with selenium yeast. J. Dairy Sci. 93:4644-4650.

Wang, C., Q. Liu, W. Z. Yang, Q. Dong, X. M. Yang, D. C. He, P. Zhang, K. H. Dong, and Y. X. Huang. 2009. Effects of selenium yeast on rumen fermentation, lactation performance and feed digestibilities in lactating dairy cows. Livest. Sci. 126:239-244.

Weiss, W. P. 2003. Selenium nutrition of dairy cows: Comparing responses to organic and inorganic selenium forms. Pages 333-343 in Nutritional Biotechnology in the Feed and Food Industries. Proc. Alltech's 19th Ann. Symp. T. P. Lyons and K. A. Jacques, ed. Nottingham University Press, Nottingham, UK.

Wichtel, J. J., A. L. Craigie, H. Varela-Alvarez, and N. B. Williamson. 1994. The effect of intraruminal selenium pellets on growth rate, lactation and reproductive efficiency in dairy cattle. N. Z. Vet. J. $42: 205-210$. 